\title{
GESTÃO DE PESSOAS: COMUNICAÇÃO INTERPESSOAL, MOTIVAÇÃO E LIDERANÇA
}

\section{ARTIGO ORIGINAL}

MEDEIROS, José Marcos de ${ }^{1}$

MEDEIROS, Sanmily Silva de ${ }^{2}$

SILVA, Sandra Barbosa da ${ }^{3}$

MOURA, Manoel ${ }^{4}$

MEDEIROS, José Marcos de. Et al. Gestão de pessoas: Comunicação interpessoal, motivação e liderança. Revista Científica Multidisciplinar Núcleo do Conhecimento. Ano 04, Ed. 10, Vol. 04, pp. 49-61. Outubro de 2019. ISSN: 24480959, Link de acesso: https://www.nucleodoconhecimento.com.br/educacao/motivacao-e-lideranca

\section{RESUMO}

Este trabalho científico apresenta uma abordagem sobre a nova perspectiva na área da comunicação, motivação, liderança e as necessidades de se adaptar aos novos meios de comunicação. Não temos como objetivo apresentar uma receita pronta para elucidar os problemas de comunicação dentro das organizações ou criar métodos de relacionar-se, mas fomentar a discussão por entender sua relevância nos dias atuais,

1 Pós-Graduado em Pedagogia: Gestão e Planejamento Escola pela FACOL Faculdade Escritor Osman da Costa Lins.

${ }^{2}$ Graduanda em Enfermagem pela Universidade Federal de Pernambuco.

3 Pós-Graduada em Pedagogia: Gestão e Planejamento Escola pela FACOL Faculdade Escritor Osman da Costa Lins.

${ }^{4}$ Mestre em Comunicação. Jornalista, professor dos cursos de Pós- Graduação da FACOL. 
já que este tema é bastante discutido e muito procurado para se trabalhar em equipe, pois se trata da psicologia humana. Dado a relevância da comunicação interpessoal, se faz necessário esclarecer alguns pressupostos no que diz respeito às formas de comunicar-se, relacionar-se, como também os fatores principais para uma liderança eficaz e que contribuam para diferenciação do gestor de pessoas, visando o alcance da perspectiva empresarial.

Palavras-chaves: comunicação interpessoal, motivação, liderança.

\section{INTRODUÇÃO}

O presente artigo apresentará soluções aos problemas da comunicação interpessoal, abordando os temas: Comunicação e Relação Interpessoal, Comunicação e Responsabilidade Social, Motivação e Liderança. Ambas com o objetivo de atender as necessidades de comunicação dos indivíduos.

Estes temas são bastante discutidos e muito procurados para se trabalhar nas organizações, pois são temas que tratam da psicologia humana. Os assuntos trabalhados estão sendo explicados um a um, desde a definição e o que se deve fazer para solucionar alguns problemas de falta de comunicação, explicando a razão destas causas.

Nos aspectos de motivação e liderança, este trabalho trás algumas dicas de como ser um bom líder e como manter uma equipe sempre motivada.

No cotidiano em relação aos temas vivenciados até recentemente, quase todo o ajuste mútuo de uma organização acontecia em decorrência de Comunicação Pessoal entre colegas de trabalho, todavia, com o advento da internet isso mudou. A distância geográfica já não impede a comunicação necessária. Os líderes podem coordenar atividades de trabalho distantes, a milhares de quilômetros. Além disso, o tempo não interfere na coordenação por ajuste mútuo. A vantagem é que a necessidade de hierarquia é reduzida, o que resulta em uma estrutura mais horizontal que permite participação dos empregados. Trabalhadores que precisam de informações sobre um 
determinado produto podem consultar boletins localizados nos computadores da empresa. Nas salas de videoconferência, os funcionários podem conversar entre si sobre problemas e dificuldades do trabalho sem a necessidade de deslocamentos rotineiros.

Segundo Luck,(1996) a comunicação dá às pessoas a oportunidade de controlarem o próprio trabalho, assumirem autoria e sentirem-se responsáveis, conquistando assim, sua autonomia. Nesse contexto entende-se que ser responsável pelas próprias escolhas, é dever de cada um, portanto, praticar tais conhecimentos em comunicações diárias proporcionará crescimento do relacionamento interpessoal.

\section{COMUNICAÇÃO E RELAÇÃO INTERPESSOAL}

Quando se fala em Comunicação, vem logo a mente a fala propriamente dita sobre os métodos de Conversação, os meios que a empresa encontra para levar informações a todos da sociedade. Mas comunicar-se não implica somente nisto, vai muito além desta simples resposta; a comunicação é o mecanismo através do qual as relações humanas existem e se desenvolvem, ou seja, a comunicação é a troca de informações entre as pessoas, então, comunicar representa compartilhar, dividir, tornar comum a todos e trazer ao conhecimento de todos. Dentro deste processo de comunicar-se existem os chamados ruídos da comunicação que são as interferências ou barreiras que podem atrapalhar o processo e poderá trazer falhas e até prejuízos para organização.

Marchiori afirma;

É fundamental a existência de ambientes de trabalho que preservem a satisfação do funcionário e o respeito ao ser humano. Assim, quanto maior for o envolvimento do funcionário com a organização maior será o seu comprometimento (MARCHIORI 2008, p. 209)

Ou seja, as pessoas atuarão de acordo com as informações que recebem o que pode provocar conflitos entre si ou não.

Segundo Moscovici; 
Nenhum grupo pode existir sem comunicação: a transferência de significados entre seus membros. Apenas através da transferência de significados de uma pessoa para outra é que as informações e as idéias conseguem ser transmitidas. A comunicação, contudo, é mais do que simplesmente transmitir um significado. Ela precisa ser compreendida. Em um grupo em que um indivíduo fala apenas alemão e os demais não sabem o idioma, ele não conseguirá ser bem compreendido. Portanto, a comunicação precisa incluir a transferência e a compreensão de mensagem. (ROBBINS, 2007, p. 184)

A vida se faz pelo meio da comunicação, todo mundo precisa se comunicar para conseguir alguma coisa. A idéia tem que ser dirigida de uma pessoa para outra afim que a mensagem seja captada da melhor forma possível.

\section{COMUNICAÇÃO FORMAL}

É aquela claramente definida, e até mesmo desenhada, seguindo as linhas do organograma, fornecendo uma nítida visão da origem das transmissões de informações planejadas para a organização.

Kunsch(2003) considera que a formalidade da Comunicação deriva da estrutura normativa da organização e através de diversos veículos estabelecidos pela instituição como os impressos, os auditivos, os eletrônicos, os visuais e os telemáticos entre outros.

Segundo Goldhaber (1991) "Formalmente, as transmissões de mensagens podem ser representadas pelas tarefas designadas aos colaboradores." Ou seja, através da realização do trabalho, o funcionário se comunica formalmente com seus superiores, seus pares e subordinados.

\section{COMUNICAÇÃO INFORMAL}

Em relação à informalidade no processamento de comunicação nas organizações: Kunsch (2003) afirma que esta prática se dá nas relações sociais intra-organizacionais e provém da busca das pessoas por informações organizacionais para realização de tarefas e questões relacionadas à vista pessoal do funcionário. 
Corroborando com Kunsch e Goldhaber, que os integrantes das organizações relacionam com outros colaboradores por motivos e assuntos paralelos ao trabalho gerando relações de informalidade.

A comunicação e relação interpessoal são ferramentas muito importantes, pois para realizar os objetivos profissionais e pessoais precisa-se de pessoas que acreditem no sonho de cada um e participem dele para o mesmo possa ser concretizado.

Segundo Heloisa Lück:

Essa participação dá às pessoas a oportunidade de controlarem o próprio trabalho, assumirem autoria sobre o mesmo e sentirem-se responsáveis por seus resultados, portanto construindo e conquistando sua autonomia. Daí porque a participação competente é o caminho para a construção da autonomia. (LÜCK, 2006, p 51)

$O$ ato de saber comunicar-se é uma ferramenta fundamental para a construção do relacionamento, pois ela oferece a possibilidade de gerar conhecimento, entendimento, comprometimento, acumulação e ação.

O conteúdo falado por um emissor pode ser interpretado de forma diferente pelo receptor. Portanto para que a comunicação flua de forma harmoniosa, precisa-se ter um bom relacionamento interpessoal, cativando as pessoas, estabelecendo laços empáticos e transmitindo confiança através da boa postura, gestos, palavras e voz.

Uma maneira de conquistar as pessoas é usar palavras adequadas ao momento em que se vive: saber agradecer, cumprimentar, elogiar, não falar mal de algum indivíduo que não esteja participando da conversa e sendo um ouvinte ativo, muitas vezes deixando de lado seus próprios interesses para escutar alguém. Sabendo que, ser responsável pelas próprias escolhas é dever de cada um, então praticar tais conhecimentos diariamente abrirá canais de comunicação com as mesmas e crescerá o relacionamento interpessoal.

De acordo com o PCN: 
A Comunicação entre os homens pode ser praticada em várias dimensões, que desde a cultura como um todo, até a conversa amena entre duas pessoas ela pode ser fonte de riquezas e alegrias: $O$ contato que o artista estabelece com o seu público, a discussão cientifica sobre alguns temas relevantes, o debate caloroso de olhares entre amantes. (PCN, 2001, Vol. 8 p.31)

E como isto funciona nas organizações? É certo que para haver uma boa administração depende de uma boa comunicação entre os colaboradores de uma empresa só terão a ganhar em produtividade, pois pessoas estimuladas, ouvidas e representadas produzem melhor e muito mais. Portanto, um bom gestor é aquele que sabe respeitar os limites dos outros e comunicar-se de forma coerente e clara além das diferenças individuais.

Bordenave enfatiza que:

A Comunicação serve para que as pessoas se relacionem entre si, transformando-se mutuamente e a realidade que as rodeia. Sem a Comunicação cada pessoa seria um mundo fechado em si mesmo. Pela Comunicação as pessoas compartilham experiências, ideias e sentimento. Ao se relacionarem como seres interdependentes, influenciam-se mutuamente e, juntas, modificam a realidade onde estão inseridas. (BORDENAVE, 2003, p.36)

E com os avanços das tecnologias, e o mundo virtual entrando cada vez mais nos lares domésticos o contato humano já esta saindo de moda. Vivemos em uma sociedade moderna que reinventou as formas de relacionamentos interpessoais fazendo da distância física apenas particularidade, às vezes esta distância é até esquecida e pensa-se está lado a lado. Todavia esta instantaneidade de contatos, lugares e pessoas, só acontece porque existe uma ferramenta tecnológica intermediando e gerenciando estas relações. Por um lado, a rapidez do "mundo online", de outro lado a parte vazia da impessoalidade que acaba por tornar tudo mecânico. Conforme coloca Kunsch (2003) é exatamente no âmbito desses cenários mutantes e complexos que as organizações operam, lutam para se manter e cultivar seus valores.

Analisando mais a fundo o mundo corporativo deve-se pensar em alguns, pontos primordiais desse processo, onde no processo do on-line, diz respeito à eficiência 
organizacional, o que não sobrevive mais as deficiências do processo, nem à falta de qualidade dos produtos e serviços ao desequilíbrio da sinergia produtiva do capital humano. Mas se der um colapso em alguns destes itens pode refletir no mercado uma desvantagem. Portanto para que haja um equilíbrio é preciso que trabalhe em conjunto as relações interpessoais e a comunicação, percebendo que a qualidade dos relacionamentos humanos é fundamental para a educação social, inclusive a organizacional e que cada vez mais o pensar no todo são pontos primordiais para uma boa relação e uma ótima produtividade dentro da empresa conforme coloca Ashley (2002) "Parece licito afirmar que hoje em dia as organizações precisam estar atentas não só a suas responsabilidades econômicas e legais mas também as suas responsabilidades éticas, morais e sociais." Ou seja, o foco tem que ser comunicação e não os meios de comunicação, pois para que haja qualquer tipo de comunicação interpessoal tem que haver primeiro o homem o qual é o ser mais importante dentro da empresa.

\section{COMUNICAÇÃO E RESPONSABILIDADE SOCIAL}

Dentro do cenário de preocupação com a responsabilidade social, que envolve mudança de atitudes e de valores por parte das organizações é relevante destacar a atuação dos profissionais de comunicação, pois eles têm uma função estratégica dentro das organizações, no sentido de planejar e divulgar as ações sociais que passam a fazer parte do meio empresarial e estabelecem padrões éticos no relacionamento com o público, pois como afirma Pinto (2001) ações duradouras, comunicadas de forma adequada, trazem frutos duradouros.

Por isso é necessária uma nova postura das empresas que implique em uma nova realidade de atuação dos comunicadores. É preciso que a comunicação das organizações reflita este novo ambiente empresarial. As organizações empresariais que pretendem sobreviver no mercado obtendo lucro e sucesso terão que adotar uma atitude transparente diante de seu público. Cada vez mais se torna relevante apresentar de forma clara e objetiva a missão e a filosofia econômica e social da organização. 
As empresas precisam solidificar seu relacionamento com o público com base na responsabilidade e honestidade. Quando firmamos isso, estamos destacando o papel das relações públicas na realidade de uma postura ética por parte das organizações. De acordo com Nash (1993) "Entre os valores compreendidos pela conduta ética nos negócios estão à honestidade, justiça, respeito pelos outros, serviço, palavra, prudência e confiabilidade."

A responsabilidade social praticada pelas organizações deve ser reforçada pelas estratégias de comunicação, pois é através delas que a organização se mostra comprometida. Dessa forma, é relevante a definição de um posicionamento junto ao seu público. Como enfatiza Reis e Trout (1999) "O posicionamento é um sistema organizado para se encontrar uma janela para a mente. Baseia-se no conceito de que a Comunicação só pode ter lugar no momento certo e na circunstância certa." Portanto, é isto que as organizações socialmente responsáveis precisam ter um lugar na vida e na mente de seu público, onde elas sejam lembradas como organizações empresariais comprometidas com os problemas sociais.

De acordo com Henrique:

Na cena contemporânea, as relações públicas serão facultadas a missão de interagir entre os interesses das comunidades e da empresa, detectando necessidades e alternativas de desenvolvimento social e econômico das populações, propondo e desenvolvendo formas de solucionar problemas sociais, articulando o apoio e promovendo a elaboração de projetos que visem erradica carências sociais de todo o tipo. (HENRIQUE 2001, p.12)

Através do planejamento e execução de ações socialmente responsáveis, que consolidem os projetos relacionados ao meio ambiente, a melhoria do espaço de trabalho, entre outros, um novo posicionamento organizacional e novas relações, fundamentadas numa postura ética, deverão ser estabelecidas com os funcionários, comunidade e consumidores, enfim, com todos os colaboradores.

Compreende-se desta forma, que os profissionais da comunicação passam a desenvolver junto às organizações uma postura social e ética mais voltada à qualidade de vida social. 


\section{MOTIVAÇÃO E LIDERANÇA}

Motivação quer dizer a força que energiza, dirige e sustenta os esforços de uma pessoa. levando o indivíduo a agir em determinada direção rumo a um objetivo desejado. Ela nasce de uma necessidade, como coloca Maslow, (1954) na sua teoria da hierarquia das necessidades, para ele estas necessidades se desenvolvem em função da ocorrência da carência e satisfação do indivíduo.

As necessidades verdadeiras da motivação humana começam a aparecer e como na administração cientifica teve um número crescente de fracassos, então surgiu Elton Mayo, (1933) para resolver esses problemas. Ele elaborou muitas experiências, reconhecendo que os parceiros colaboradores buscavam mais que dinheiro no trabalho e precisavam de mais estímulos. Observou que eles desejavam ser considerados como membros significativos dentro dos grupos dos quais faziam parte dentro da empresa. Quando os empregados conseguem um sentimento de valor pessoal e participam das decisões que afetam o seu trabalho, ficam mais motivados e produzem com mais qualidade. Os incentivos como segurança estimam afiliação, interesse pelo trabalho, êxito e dão início ao movimento de relações humanas.

Estes estudos serviram para mostrar que a produtividade só aumentava porque os trabalhadores conseguiam um sentimento maior de valor pessoal, participavam das decisões que sua empresa ia tomar, ou seja, tinham um envolvimento no próprio trabalho, sentiam-se seguros e devido a este tratamento passivo e amistoso eles tinham a oportunidade de ganhar mais dinheiro devido ao sistema de recompensa como incentivo.

E com isto os trabalhadores se sentiam mais motivados, com mais alegria e cumpriam suas metas com maior eficácia e satisfação.

Segundo Chiavenato (1994), "Assim, em troca desse elemento simbólico e intercambiável (dinheiro), o homem é capaz de empenhar parte de si mesmo do seu esforço e de sua vida." Portanto, pode-se afirmar que o salário é um dos principais 
fatores da motivação, pois funcionários bem remunerados desempenham suas tarefas cada vez melhor.

Mas afinal, o que é motivação? Motivação é o desejo de exercer altos níveis de esforços em direção a determinados objetivos, metas organizacionais e condicionados pela capacidade de satisfazer objetivos ou metas individuais. Ela depende da direção traçada, força e intensidade do comportamento, ou seja, o esforço do indivíduo e duração de sua persistência. Uma necessidade significa uma carência interna do ser e que cria um estado de tensão no organismo. As teorias de conteúdo de motivação procuram dar uma visão geral das necessidades do indivíduo.

E afinal, o que é liderança? Para Chiavenato (1999) "É um processo chave em todas as organizações, onde $o$ administrador deveria ser um líder para lidar com as pessoas que trabalham com ele." A liderança é uma forma de influência, e a mesma é uma transação interpessoal em que uma pessoa age para provocar ou modificar o comportamento da outra, de maneira intencional.

Existem três diferentes abordagens teóricas a respeito da liderança. E cada uma com sua respectiva explicação. A teoria de traços de personalidade que aborda e sintetiza as características de personalidade possuídas pelo líder como: otimismo, inteligência, empatia, flexibilidade, perspicácia, comunicabilidade e entusiasmo etc. A teoria sobre estilos de liderança onde a abordagem trata das maneiras e estilos de se comportar adotados pelo líder que são: liberalismo, autocracia, democracia e por último, mas não menos importante, a teoria situacional de liderança que diz respeito ao modo de como adequar o comportamento do líder as circunstâncias da situação.

A partir destas teorias surgiram algumas dicas para que o líder possa liderar com maior facilidade e tornar ágil a resolução dos problemas mais enfrentados no dia a dia das empresas. Em primeiro lugar é necessário ficar atento ao que está por vir, identificando o desafio ou projeto de forma mais concreta possível, preparando a equipe o quanto antes melhor. O líder nunca deve fazer promessas que não possa cumprir especialmente nunca prometer a vitória antes do desenvolvimento do projeto ou desafio proposto. Deve-se ser cauteloso, construir um bom plano de ação e traçar 
metas que sejam concretas, atingíveis que possa conquistar a confiança de todos, mostrando razões para seguir adiante.

O líder deve aprender com os erros, identificando e registrando tais lições reconhecendo que com a derrota, sempre se aprende algo novo. Deve descobrir o que a equipe poderia ter feito melhor. O líder deve sempre vigiar a si mesmo, nunca demonstrar pessimismo, jamais ter comportamentos que não gostaria de ver na sua equipe e nunca demonstrar estar pra baixo ou qualquer outro sentimento ruim. Jamais ficar muito tempo em silêncio, pois a falta de diálogo entre você e sua equipe leva a falta de comunicação entre eles e os clientes.

É preciso dar ênfase aos acertos e saber reconhecer os pontos negativos de falha para a melhoria, mas para a motivação é necessário algo mais, ter consciência do que foi bem feito, identificar e discutir com a equipe os aspectos positivos e negativos, os acertos do projeto e reconhecer o esforço de cada membro da equipe mesmo que não tenha alcançado o resultado esperado. Tem que ser generoso no momento certo, isto perante a equipe toda. E é importante que ele esteja sempre motivado, tirando da cabeça pensamentos negativo e compreender que a derrota faz parte da carreira e da vida, mas para sair dela é preciso continuar em frente e se o próprio líder estiver desmotivado é impossível realizar qualquer tarefa com efetividade máxima.

O trabalhador sente-se valorizado e feliz quando é reconhecido pelos seus feitos. E um bom líder faz parte de todo este engajamento, onde trabalha motivado porque alguém tem confiança nele e na sua capacidade de resolver problemas. O líder tem que ter influência capaz de levar uma equipe em direção ao alcance do bem comum, atingindo metas e objetivos da organização. Elas precisam de liderança e administração fortes para atingir um ótimo resultado.

O líder tem um papel crucial para a compreensão do comportamento da equipe onde está inserido, pois é o líder quem oferece direção em relação ao alcance das metas e objetivos. Além disso, o sucesso depende do reconhecimento do nível de apoio da equipe, da experiência, da inteligência do líder, das características dos liderados, da personalidade de cada um, criatividade e capacidade e acima de tudo da motivação 
dos funcionários, assim como diz o provérbio "Você não pode motivar um cavalo a beber água, mas pode levá-lo até o rio" (autor desconhecido), logo, preparar o terreno já ajuda, pois a equipe pode chegar até o seu posto de trabalho, mas se não estiverem motivados a produção não acontecerá da maneira desejada, onde o que a move no momento não esta atuando que é a motivação.

\section{CONCLUSÃO}

A partir das informações obtidas durante a pesquisa vimos que a comunicação tratase de meios de conversações para levar informações a todos da sociedade, onde este processo não acontece de forma adequada o que dificulta o crescimento organizacional. A comunicação, a relação interpessoal e motivação são a base para liderança, mas para que isso aconteça é preciso que haja a participação por meio de todos que fazem a empresa.

Essa participação dá às pessoas a oportunidade de controlarem o próprio trabalho, assumindo autoria sobre o mesmo e sentirem-se responsáveis por seus resultados então, praticar tais conhecimentos em comunicação abrirá outros canais de comunicação e crescerá o relacionamento interpessoal.

Observamos que nas relações estabelecidas em uma equipe há um líder que transmite as subordinadas atividades realizadas diariamente, onde o mesmo deve levar em conta a diversidade de seus funcionários quando adotar um determinado estilo de comunicação. Para que haja retorno e aceitação é preciso capacitar os colaboradores de modo a obter pessoas cada vez mais preparadas para assumir as responsabilidades e enfrentar os obstáculos e desafios, assim participarem das decisões que afetam seu trabalho, dando-Ihes responsabilidade e a fim de sentiremse motivados a produzirem mais e melhor. Acreditamos que o incentivo estimula 0 valor pessoal e aumenta o interesse em mostrar liderança e competência na equipe.

Acreditamos que essa liderança influência tanto no crescimento como na queda da equipe, por isto um líder deve ser cauteloso e saber aonde quer chegar, pois ele irá ter dificuldade de promover comunicação entre a equipe se o próprio não exercer essa 
função de comunicação entre os colegas, assim o líder é visto como uma pessoa que traz benefícios não somente a empresa, mas também para cada membro de equipe. Sendo assim é preciso comunicar-se para que possamos transformar e partilhar as relações interpessoais entre os seres interdependentes para que modifiquem a realidade onde estão inseridas.

\section{REFERÊNCIAS}

ASHLEY, Patrícia Almeida (Coordenação). Ética e responsabilidade social nos negócios. São Paulo, Saraiva 2002.

BORDENAVE, Juan E. Diaz. O que é Comunicação. São Paulo. Brasiliense, $1^{\text {a }}$ Ed. 2009.

CHIAVENATO, Idalberto. Gerenciando pessoas. Makron Books. $3^{\text {a }}$ Ed. São Paulo, 1994.

GOLDHABER, Geraldo M. Comunicación Organizacional. México. Diana, 1991.

HENRIQUE, M.S.; NETO, J. AS. Comunicação e mobilização social: estratégias de atuação das organizações do terceiro setor na área da comunicação. In Anais do XXIV. Congresso Brasileiro de ciências da Comunicação, 2001. Campo Grande/MS. Intercom, 2001 (CDROM).

KUNSCH, Margarida Maria Krohling. Planejamento de Relações Publicas na Comunicação Integrada. São Paulo. Sunmus, 2003.

LUCK, Heloisa. A Gestão Participativa na Escola. Petrópolis , RJ: Vozes. 2006.

MATTELART, Amand. Historia das teorias da comunicação. São Paulo. Edições Loyola, 1999.

MOSCOVICl, Agostinho. Psicologia Interpessoal. Treinamento em Grupo. Editora José Olimpio, 12ª edição Rio de Janeiro,2002. 
NASH, Laura.Ética nas empresas: Boas intenções à parte. São Paulo. Makron Books, 1993.

Paramentos Curriculares Nacionais: Apresentação dos temas transversais: ética/Ministerio da Educação. Secretaria da Educação Fundamental, 3ª Ed. Brasília. A Secretaria, 2001.

PINTO, Chiristina Carvalho. Valor ou modernismo? Guia da boa cidadania Corporativa. Porto de integrante da revista exame. São Paulo. Ed. 754. 2001.

RIES, A; TROUT, J. Posicionameto - a batalha pela sua mente. São Paulo: Pioneira, 1999.

ROBBINS, Stephen P. Comportamento Organizacional. 11edª . São Paulo:Pearson Prentice Hall, 2005.

MARCHIORI, Marlene. Faces da Cultura e da comunicação organizacional. $2^{\circ}$ Edição.

São Caetano do Sul, São Paulo: Difusão Editora, 2008

MASLOW, Abraham.Motication and. Personality, Harper \& Row, 1954.

MAYO, Elton. The Human Problemas of an Industrial Civilization. New York, The Macmillan co., 1933 (Livre Tradução).

MARÍN, I.; PENÓN, S. Que brinquedo escolher? Revista Pátio Educação Infantil, ano I, n. 3, p. 29-31, dez. 2003/mar. 2004.

Enviado: Setembro, 2019.

Aprovado: Outubro, 2019. 